\title{
Genotoxic potential of Cotinus coggygria Scop. (Anacardiaceae) stem extract in vivo
}

\author{
Sanja Matic ${ }^{1}$, Snezana Stanic ${ }^{1}$, Desanka Bogojevic ${ }^{2}$, Slavica Solujic ${ }^{3}$, Nevena Grdovic ${ }^{2}$, \\ Melita Vidakovic ${ }^{2}$ and Mirjana Mihailovic ${ }^{2}$ \\ ${ }^{1}$ Department of Biology and Ecology, Faculty of Science, University of Kragujevac, Serbia. \\ ${ }^{2}$ Department of Molecular Biology, Institute for Biological Research, University of Belgrade, Serbia. \\ ${ }^{3}$ Department of Chemistry, Faculty of Science, University of Kragujevac, Serbia.
}

\begin{abstract}
The intention was to evaluate the possible in vivo genotoxic potential in different cell-types, of a methanol extract obtained from the plant stem of Cotinus coggygria Scop., using the sex-linked recessive lethal (or SLRL) test and alkaline comet assay. The SLRL test, revealed the genotoxic effect of this extract in postmeiotic and premeiotic germ-cell lines. The comet assay was carried out on rat liver and bone marrow at 24 and $72 \mathrm{~h}$ after intraperitoneal administration. For genotoxic evaluation, three concentrations of the extract were tested, viz., 500, 1000 and $2000 \mathrm{mg} / \mathrm{kg}$ body weight (bw), based on the solubility limit of the extract in saline. Comet tail moment and total scores in the group treated with $500 \mathrm{mg} / \mathrm{kg}$ bw, 24 and $72 \mathrm{~h}$ after treatment, were not significantly different from the control group, whereas in the groups of animals, under the same conditions, but with 1000 and $2000 \mathrm{mg} / \mathrm{kg}$ bw of the extract, scores were statistically so. A slight decrease in the comet score and tail moment observed in all the doses in the $72 \mathrm{~h}$ treatment, gave to understand that DNA damage induced by Cotinus coggygria extract decreased with time. The results of both tests revealed the genotoxic effect of Cotinus coggygria under our experimental conditions.
\end{abstract}

Key words: comet assay, Cotinus coggygria, extract, genotoxic effect, SLRL.

Received: July 7, 2010; Accepted: November 12, 2010.

Many plant extracts have been used as sources of medicinal agents, in the cure of urinary tract infections, cervicitis vaginitis, gastrointestinal disorders, respiratory diseases, cutaneous affections, helminitic infections and inflammatory processes (Brantner and Grein, 1994; Meyer et al., 1996). Nevertheless, of late, the safeness of their use has been questioned in view of the reports of illness and fatalities (Stewart et al., 1999; Ernst, 2002; Veiga-Junior et al., 2005). Considering the complexity of herbs in general and their inherent biological variation, it is now necessary to evaluate their safety, efficacy and quality (WHO, 2002).

Cotinus coggygria is one of two species constituting a minor genus of the family Anacardiaceae, viz., Cotinus coggygria Scop. (syn.: Rhus cotinus L.) itself and Cotinus obovatus Raf., the American smoketree. Its wide distribution extends from southern Europe, the Mediterranean, Moldova and the Caucasus, to central China and the Himalayas (Novakovic et al., 2007). Plants of the family Anacardiaceae have a long history of use by various peoples for medicinal and other purposes. Rhus glabra is traditionally used in the treatment of bacterial diseases such as

Send correspondence to Sanja Matic. Institute of Biology and Ecology, Faculty of Science, University of Kragujevac, Radoja Domanovica 12, Serbia. E-mail: msmaticsanja @yahoo.com. syphilis, gonorrhea, dysentery and gangrene, while $R$. coriaria, besides its common use as a spice consisting of ground dried fruits with salt, is also widely used as a medicinal herb, particularly for wound healing (Rayne and Mazza, 2007). In folk medicine, Cotinus coggygria is routinely used as an antiseptic, anti-inflamatory, antimicrobial and antihaemorragic agent in wound-healing (Demirci et al., 2003), as well as for countering diarrhea, paradontosis, and gastric and duodenal ulcers (Ivanova et al., 2005).

This study was undertaken with the aim of determining, by way of SLRL testing and comet assay, the in vivo genotoxic effects of acute administration of a Cotinus coggygria stem extract on different models of eukaryotic organisms.

Cotinus coggygria plants were collected at a place called Rujiste, in the Rogozna mountain, in northern Kosovo, during the period May to June 2007. The species was identified and a voucher specimen (16178, BEOU) deposited at the Department of Botany, the Faculty of Biology, University of Belgrade. The extract was obtained, first by breaking air-dried stem (1.157 g) into small pieces $(2-6 \mathrm{~mm})$ with a cylindrical crusher, and then by applying the Soxhlet procedure using methanol $(500 \mathrm{~mL})$ as solvent. The extract, firs filtered through a paper filter (Whatman, 
No. 1), was then evaporated so as to remove the solvent. The residue ( $32 \mathrm{~g}$ ) was stored in a dark glass bottle for further processing.

The sex-linked recessive lethal test for mutagenicity (SLRL test) was carried out with laboratory stocks of Drosophila melanogaster (obtained from the Umea Stock Centre, Sweden). The stocks were maintained and all experiments performed under optimal conditions $\left(25{ }^{\circ} \mathrm{C}, 60 \%\right.$ relative humidity and a $12 / 12 \mathrm{~h}$ light/dark regime) on a standard nutritive medium for Drosophila, (corn flour, yeast, agar, sugar and nipagin to prevent the occurrence of mould and infections).

Three-to-four-days-old wild type males of Drosophila melanogaster (test group $1, \mathrm{~N}=30$ ) were left to starve in empty bottles for $5 \mathrm{~h}$ and then transferred and exposed to a $1 \%$ sucrose (as negative control), according to the method of Lewis and Bacher (1968). The second group (test group $2, \mathrm{~N}=15)$ was treated with $0.75 \mathrm{ppm}$ ethyl-methane sulfonate (EMS) in 1\% sucrose (positive control). The third group (test group $3, \mathrm{~N}=15$ ) was treated with a $5 \%$ plant extract dissolved in sucrose. After $24 \mathrm{~h}$ of treatment and a further $24 \mathrm{~h}$ resting on fresh medium, males were individually mated to two-to-five-days-old virgin Basc females (brood I). The males were then remated in fresh vials with three other virgin Basc females at two-to-three-days intervals (brood II), so as to test all germ-cell stages for the presence of mutations. Once again, the males were then transferred to fresh vials containing three Basc virgins (brood III). These males remained with the females for three days, to then be removed. The females were left alone for five days to lay eggs, and then removed. When the $F_{1}$ flies emerged, brother-sister mating was allowed, whereupon ten pairs from each progeny were individually placed together, from the same number. The $F_{2}$ generation was examined for the presence or absence of wild-type males. It was noted that, when this was so, these all contained the same treated $\mathrm{X}$-chromosome in hemizygous condition. Any recessive lethal therein would be expressed before the adult stage, whereat males would not emerge. Cells exposed in successive spermatogenesis stages were tested for induced mutations, to thus check the effects on postmeiotic (spermatozoa, spermatids), meiotic (spermatocytes) and premeiotic (spermatogonia) cells (Würgler and Graf, 1985).

Two to two-and-half-months-old male albino rats of the Wistar strain (Rattus norvegicus), each weighing 220-250 g, were used for the comet assay. The rats were kept in an experimental room under controlled conditions of temperature and humidity, with food and water available ad libitum. Lighting was controlled to provide $12 \mathrm{~h}$ artificial light followed by $12 \mathrm{~h}$ darkness. All animal procedures had been previously approved by the Ethical Animal Care and Use Committee of the Institute for Biological Research, Belgrade, which acts in accordance with the Guide for the Care and Use of Laboratory Animals, published by the US National Institutes of Health (NIH Publication No. $85 / 23$, revised 1986).

In order to evaluate the genotoxicity of the Cotinus coggygria stem extract, rats were divided into four groups of five animals each. For three of the groups, each received (i.p.) a single dose of different concentrations of extract disolved in saline solution: 500, 1000 and $2000 \mathrm{mg} / \mathrm{kg}$ bw. These concentrations were based on the solubility limit of the methanol extract of Cotinus coggygria in saline solution. The fourth group (control), received a saline solution. Four separate experiments were carried out. The animals were sacrificed by decapitation 24 and $72 \mathrm{~h}$ after treatment. Liver and femur bone marrow, obtained from each group of animals, was quickly removed and separately processed, so as to obtain cell suspensions.

The alkaline version of the comet assay was carried out by the standard procedure originally described by Singh et al. (1988). Immediately prior to analysis, the slides were stained with $90 \mu \mathrm{L}$ of SYBR GREEN I (Sigma-Aldrich, S 9430). Comets were visualized and captured with the $40 \mathrm{x}$ objective lens of a Leica DMLB fluorescence microscope, attached to a CCD camera. One hundred comet images per slide were randomly captured and analyzed. The extent of DNA damage was measured by means of two complementary methods, the tail moment quantitative method and a qualitative method of damage distribution. Comets, first analyzed by the visual scoring method, as described by Collins (2004), were then classified into five categories, defined as types $0,1,2,3$ and 4 , where 0 indicates no or very low damage, and 1, 2 and 3 low, medium and long DNA migration, respectively, with 4 as the highest level of degradation, viz., comets with very small heads and long tails. The total score was calculated by the following equation modified from Manoharan and Banerjee (1985): (\% cells in class $0 \times 0)+(\%$ cells in class $1 \times 1)+(\%$ cells in class $2 \times 2)$ $+(\%$ cells in class $3 \times 3)+(\%$ cells in class $4 \times 4)$, to finally appear in a 0 (all undamaged) to 400 (all maximally damaged) range. Images were analyzed with software TriTekCometScore Freeware v1.5 available at web page AutoComet.com.

For SLRL testing, the frequency of sex-linked recessive lethal cultures was calculated according to the ratio between the numbers of lethal cultures and the total number of treated X-chromosomes. The total number of treated $\mathrm{X}$-chromosomes is equal to the sum of lethal and non-lethal cultures. The significance of percentual differences in lethal cultures was arrived at by testing for large independent samples, and then testing the difference between proportions (Petz, 1985). For comet analysis, average tail moment and standard deviation per treatment were obtained. Variance analysis was performed by using one-way analysis (ANOVA). Variance homogeneity and data distribution were determined with the Levene and Kolmogorov-Smirnov tests, respectively. Post-hoc comparison between control and treated groups was performed with a T3 Dunnett or 
Bonferroni test when variance was not homogeneous. Statistical analysis was performed using the SPSS statistical software package, version 10.0 for Windows. The results were considered to be statistically significant at $\mathrm{p}<0.05$.

From a phytomedicinal point of view, the evaluation of genotoxicity is of particular importance, since the genotoxic effects of chemicals or complex mixtures may be crucially important at the population level.

In the present study, the genotoxic effect of a Cotinus coggygria extract was observed via SLRL test and comet assay using Drosophila melanogaster as an insect and Wistar rats as a mammal model.

Various mechanisms are involved in this form of genotoxicity testing. Essentially, the SLRL test is used for detecting the occurrence of mutations, both point mutations and small deletions, in the germ line. Mutations in the X-chromosome of Drosophila melanogaster are phenotypically expressed (presence or absence of white-eyed) in males carrying the mutant gene. The sex-linked recessive lethal test in Drosophila melanogaster has been proved to be an excellent screening test for the detection of natural plant mutagens (Stanic et al., 2008). Over several decades, Drosophila has been widely used as an insect model, due to its well-elucidated genetics and developmental biology. In the present study, the genotoxicity of a methanol extract of Cotinus coggygria was examined, using a short test for the detection of mutagenicity under in vivo conditions. The frequency of germinative mutations induced by the Cotinus coggygria extract in SLRL test is significantly higher than that induced by sucrose as negative control (Table 1), this being a clear indication of its mutagenic effect. Ethylmethane sulfonate in a concentration of $0.75 \mathrm{ppm}$ was shown to be clearly genotoxic, by inducing significant increases in the frequency of mutants in all the three broods. On the other hand, and in comparison, the Cotinus coggygria extract induced recessive lethal X-linked mutations in premeiotic germinative cell lines, i.e. spermatozoids and others of this line, as well as spermatocytes, while spermatids proved to be more resistant to the genotoxic effects of the extract.

Over the last decade, in vivo alkaline comet assay, besides gaining widespread use in various areas, has emerged as a standard tool in the pharmaceutical industry for assessing the safety of new drugs and, increasingly, as a means of evaluating genotoxicity testing (Tice et al., 2000; Hartmann et al., 2001; Brendler-Schwaab et al., 2005). In the present study we evaluated the extent of DNA damage by determining average tail moment and by analyzing qualitative tail length distribution in comet images. In the liver sample from animals treated with $500 \mathrm{mg} / \mathrm{kg}$ bw of the extract, no statistically significant difference in total score between treated animals and control was observed at 24 and $72 \mathrm{~h}$ after treatment (Table 2). Most of the comets remained undamaged, with only a few cells denoting minor damage (class 1), and less still medium (class 2). However, this was not the case with animals treated with 1000 and $2000 \mathrm{mg} / \mathrm{kg}$, where significant differences were noted (Table 2). In the case of rats exposed to $1000 \mathrm{mg} / \mathrm{kg} \mathrm{bw}$, this was apparent in comet tails being longer (classes 3 and 4) when compared to the control group. The highest level of DNA damage was observed in the group treated with $2000 \mathrm{mg} / \mathrm{kg}$ bw of the extract after 24 and $72 \mathrm{~h}$.

The percentage of comets assigned to damage categories in bone marrow, at 24 and $72 \mathrm{~h}$ after in vivo exposure to $500 \mathrm{mg} / \mathrm{kg}$ bw of the extract, are presented in Table 3 . With a predominance of comet class 0 and almost no presence of classes 1 and 2, no statistically significant difference between treated and untreated animals could be observed. Under the same circumstances, this was not the case in the groups treated with 1000 and $2000 \mathrm{mg} / \mathrm{kg}$ bw of the extract,

Table 1 - Frequencies of SLRL mutations after treatment of Drosophila melanogaster males with a methanol extract from Cotinus coggygria plants

\begin{tabular}{|c|c|c|c|c|c|c|}
\hline & $\begin{array}{l}\text { Sucrose negative } \\
\text { control }\end{array}$ & $\begin{array}{l}\text { EMS positive } \\
\text { control }\end{array}$ & $\begin{array}{c}\text { Cotinus coggygria } \\
\text { extract }\end{array}$ & $\mathrm{t}_{\text {sucrose/EMS }}$ & $t_{\text {sucrose/extract }}$ & $t_{\text {EMS/extract }}$ \\
\hline I broods $\mathrm{S}$ & 300 & 221 & 269 & 9.51 & 5.45 & 5.26 \\
\hline No of lethals & 5 & 73 & 34 & $\mathrm{p}<0.001 * * *$ & $\mathrm{p}<0.001 * * *$ & $\mathrm{p}<0.001 * * *$ \\
\hline$\%$ of lethals & 1.67 & 33.03 & 12.64 & & & \\
\hline II brood S & 269 & 161 & 284 & 8.38 & 2.57 & 7.04 \\
\hline No of lethals & 5 & 54 & 17 & $\mathrm{p}<0.001 * * *$ & $\mathrm{p}<0.05^{*}$ & $\mathrm{p}<0.001^{* * *}$ \\
\hline$\%$ of lethals & 1.86 & 33.54 & 5.99 & & & \\
\hline III broods S & 252 & 117 & 252 & 5.85 & 5.72 & 1.92 \\
\hline No of lethals & 6 & 30 & 43 & $\mathrm{p}<0.001 * * *$ & $\mathrm{p}<0.001 * * *$ & $\mathrm{p}<0.1$ \\
\hline$\%$ of lethals & 2.38 & 25.64 & 17.06 & & & \\
\hline $\mathrm{I}+\mathrm{II}+\mathrm{III} \mathrm{S}$ & 821 & 499 & 805 & 13.81 & 8.15 & 7.92 \\
\hline No of lethals & 16 & 157 & 94 & $\mathrm{p}<0.001 * * *$ & $\mathrm{p}<0.001 * * *$ & $\mathrm{p}<0.001 * * *$ \\
\hline$\%$ of lethal & 1.95 & 31.46 & 11.67 & & & \\
\hline
\end{tabular}

Statistically significant difference: $\mathrm{p}<0.05^{*} ; \mathrm{p}<0.01^{* *} ; \mathrm{p}<0.001^{* * *}$ 
Table 2 - DNA migration in the comet assay for the assessment of genotoxicity of Cotinus coggygria extract in the livers of albino wistar rats, 24 and $72 \mathrm{~h}$ after treatment.

\begin{tabular}{lcccccc}
\hline Treatments & \multicolumn{5}{c}{ Levels of damage } & \multicolumn{2}{c}{ Total score (mean \pm SD) } \\
\cline { 2 - 6 } & 0 & 1 & 2 & 3 & 4 & $23.20 \pm 1.10$ \\
\hline Negative control & $84.1 \pm 1.32$ & $10.6 \pm 0.40$ & $6.30 \pm 0.3$ & $0.00 \pm 0.00$ & $0.00 \pm 0.00$ & \\
C. coggygria $24 \mathrm{~h}$ & & & & & \\
$500 \mathrm{mg} / \mathrm{kg}$ & $78.8 \pm 0.42$ & $15.6 \pm 0.44$ & $5.60 \pm 0.16$ & $0.00 \pm 0.00$ & $0.00 \pm 0.00$ & $26.80 \pm 2.30$ \\
$1000 \mathrm{mg} / \mathrm{kg}$ & $43.8 \pm 0.33$ & $32.8 \pm 0.20$ & $17.7 \pm 0.40$ & $4.70 \pm 0.40$ & $1.00 \pm 0.21$ & $86.30 \pm 0.83^{*}$ \\
$2000 \mathrm{mg} / \mathrm{kg}$ & $27.2 \pm 0.26$ & $38.8 \pm 0.34$ & $25.7 \pm 0.39$ & $6.10 \pm 0.19$ & $2.01 \pm 0.21$ & $116.50 \pm 1.14^{*}$ \\
C. coggygria $72 \mathrm{~h}$ & & & & & \\
$500 \mathrm{mg} / \mathrm{kg}$ & $81.0 \pm 0.84$ & $13.4 \pm 0.16$ & $5.70 \pm 0.84$ & $0.00 \pm 0.00$ & $0.00 \pm 0.00$ & $24.80 \pm 0.45$ \\
$1000 \mathrm{mg} / \mathrm{kg}$ & $41.6 \pm 0.26$ & $45.0 \pm 0.42$ & $10.1 \pm 0.18$ & $3.10 \pm 0.24$ & $0.00 \pm 0.00$ & $74.50 \pm 1.14^{*}$ \\
$2000 \mathrm{mg} / \mathrm{kg}$ & $30.4 \pm 0.32$ & $47.2 \pm 0.35$ & $16.6 \pm 0.37$ & $2.90 \pm 0.24$ & $1.03 \pm 0.25$ & $92.10 \pm 1.22^{*}$ \\
\hline
\end{tabular}

${ }^{*}$ Significantly different from the negative control $\mathrm{p}<0.05$.

Table 3 - DNA migration in the comet assay for the assessment of genotoxicity of Cotinus coggygria extract in bone marrow of albino wistar rats, 24 and $72 \mathrm{~h}$ after treatment.

\begin{tabular}{lcccccc}
\hline Treatments & \multicolumn{3}{c}{ Levels of damage } & \multicolumn{2}{c}{ Total score (mean \pm SD) } \\
\cline { 2 - 6 } & 0 & 1 & 2 & 3 & 4 \\
Negative control & $79.8 \pm 0.41$ & $20.2 \pm 0.35$ & $0.00 \pm 0.00$ & $0.00 \pm 0.00$ & $0.00 \pm 0.00$ & $21.0 \pm 1.60$ \\
C. coggygria $24 \mathrm{~h}$ & & & & & \\
$500 \mathrm{mg} / \mathrm{kg}$ & $76.4 \pm 0.48$ & $20.4 \pm 0.43$ & $3.20 \pm 1.51$ & $0.00 \pm 0.00$ & $0.00 \pm 0.00$ & $26.8 \pm 0.24$ \\
$1000 \mathrm{mg} / \mathrm{kg}$ & $31.1 \pm 0.41$ & $40.2 \pm 0.28$ & $19.8 \pm 0.38$ & $7.40 \pm 0.36$ & $1.50 \pm 0.47$ & $108.0 \pm 0.65^{*}$ \\
$2000 \mathrm{mg} / \mathrm{kg}$ & $27.4 \pm 0.48$ & $32.1 \pm 0.27$ & $30.2 \pm 0.33$ & $6.60 \pm 0.20$ & $3.80 \pm 0.42$ & $127.5 \pm 0.43^{*}$ \\
C. $\operatorname{coggygria} 72 \mathrm{~h}$ & & & & & \\
$500 \mathrm{mg} / \mathrm{kg}$ & $72.2 \pm 0.58$ & $27.7 \pm 0.47$ & $0.00 \pm 0.00$ & $0.00 \pm 0.00$ & $0.00 \pm 0.00$ & $25.2 \pm 1.90$ \\
$1000 \mathrm{mg} / \mathrm{kg}$ & $42.3 \pm 0.42$ & $47.3 \pm 0.43$ & $8.70 \pm 0.40$ & $1.90 \pm 0.42$ & $0.00 \pm 0.00$ & $70.4 \pm 1.50^{*}$ \\
$2000 \mathrm{mg} / \mathrm{kg}$ & $27.2 \pm 0.40$ & $49.5 \pm 0.45$ & $19.10 \pm 0.2$ & $3.20 \pm 0.23$ & $1.01 \pm 0.26$ & $101.3 \pm 3.60^{*}$ \\
\hline
\end{tabular}

${ }^{*}$ Significantly different from the negative control $\mathrm{p}<0.05$.

where there was a significant increase in damages, when compared to the control group.

The average values of comet tail moment in liver and bone marrow are shown in Table 4 . Comet tail moment in the group treated with $500 \mathrm{mg} / \mathrm{kg}$ bw of the extract was not significantly different from the control group. Nevertheless, when compared to the control, there was a significant increase in tail moment at both 24 and $72 \mathrm{~h}$ after treatments with 1000 and $2000 \mathrm{mg} / \mathrm{kg}$ bw. It should be pointed out, however, that after $72 \mathrm{~h}$, a slight decrease in tail moment, both in the liver and bone marrow, was detected when compared to the $24 \mathrm{~h}$ time point.

This difference in the response seen in the comet assay and SLRL test is not surprising, since the comet assay is a rapid, simple and highly sensitive method for detecting single and double DNA strand breaks and alkali-labile sites. In contrast, the comet assay is not used to detect muta- tions, but rather to detect genomic lesions that could lead to a mutation (Gontijo and Tice, 2003).

The fact that certain plants may have genotoxic effects depends on the various compounds present in their extracts. The partial chemical analysis of the methanol extract of Cotinus coggygria, showed flavonoids, tannins and phenolic compounds to be the main compounds (Stanic et al., 2009). In a previous study, total soluble phenolic compounds in the methanol extract of Cotinus coggygria stems were determined with the Folin-Ciocalteu reagent, using pyrocatechol as a standard. In the methanol extract of $C$. coggygria (1 g), $62.50 \mathrm{mg}$ pyrocatechol equivalent of phenols was detected, while $46.76 \mathrm{mg}$ of flavonoids and $15.75 \mathrm{mg}$ of nonflavonoids were detected in $1 \mathrm{~g}$ of dry weight (Stanic et al., 2009).

Fractionation of the methanol extract from Cotinus coggygria performed by Stathopoulou et al. (2007), led to the isolation of sulfuretin, fisetin, 7,3',4'-trihydroxy-fla- 
Table 4 - Average comet tail moment and standard deviation, 24 and $72 \mathrm{~h}$ after in vivo exposure of albino wistar rats to Cotinus coggygria methanol extract.

\begin{tabular}{lccccc}
\hline Treatments & \multicolumn{2}{c}{ Tail moment - liver } & & \multicolumn{2}{c}{ Tail moment - bone marrow } \\
\cline { 2 - 3 } \cline { 5 - 6 } & $24 \mathrm{~h}$ & $72 \mathrm{~h}$ & & $24 \mathrm{~h}$ & $72 \mathrm{~h}$ \\
\hline Negative control & $2.7 \pm 0.2$ & & & $5.4 \pm 0.25$ & \\
C. coggygria & & & & $5.80 \pm 0.17$ & $5.6 \pm 0.12$ \\
$500 \mathrm{mg} / \mathrm{kg}$ & $3.1 \pm 0.11$ & $2.8 \pm 0.16$ & & $16.55 \pm 0.43^{\mathrm{a}}$ & $13.8 \pm 0.40^{\mathrm{a}}$ \\
$1000 \mathrm{mg} / \mathrm{kg}$ & $11.7 \pm 0.13^{\mathrm{a}}$ & $6.7 \pm 0.15^{\mathrm{a}}$ & & & \\
$2000 \mathrm{mg} / \mathrm{kg}$ & $17.1 \pm 0.38^{\mathrm{a}}$ & $9.6 \pm 0.32^{\mathrm{a}}$ & & $20.80 \pm 0.63^{\mathrm{a}}$ & $17.5 \pm 0.36^{\mathrm{a}}$ \\
\hline
\end{tabular}

${ }^{a}$ Significantly different from the negative control $\mathrm{p}<0.05$ (multiple comparisons T3 Dunnett test), $\mathrm{n}=5$ rats per group.

vanone, 5,7,4'-trihydroxy-flavanone, 4,2',4'-trihydroxychalcone, 2,3-dihydro-fisetin, 2,3-dihydro-quercetin, methyl gallate, $3,4,2^{\prime}, 4^{\prime}$-tetrahydroxy-chalcone, quercetin, 4',7-dihydroxy-flavanone and 4',7-dihydroxy-2,3-dihydroflavonol. Dominant compounds in the ethyl acetate partition of Cotinus coggygria were disulfuretin, sulfuretin, sulfurein, gallic acid, methyl gallate and pentagalloyl glucose (Westenburg et al., 2000).

It has been suggested that polyphenolic compounds, besides having been shown to exert anticarcinogenic effects, are potential preventives against cardiovascular and cerebrovascular diseases. Gallic acid and its derivatives are biologically active compounds which are present in several plants. This polyhydroxyphenolic acid has been reported to be a free radical scavenger, as well as an inducer of differentiation and apoptosis in leukemia, lung cancer, colon adenocarcinoma cell lines, and normal lymphocyte cells (Kawada et al., 2001; Sohi et al., 2003).

Flavonoids, such as fisetin, are naturally occurring molecules with antioxidant, cytoprotective and anti-inflammatory actions. Tannins, as one such class of compounds, are suspected of possessing protective properties. Fedeli et al. (2004) showed that they are capable of protecting against DNA breakage at low concentrations, although at high levels they could be genotoxic.

The results in this study imply that the methanol extract from Cotinus coggygria plant stems is capable of giving rise to genotoxic effects in vivo under our experimental conditions, thereby indicating caution in its use. The fact that $500 \mathrm{mg} / \mathrm{kg}$ body weight of the Cotinus extract was not genotoxic in the alkaline comet assay, and that the manifest antigenotoxic activity might be attributed to the presence of polyphenolic constituents, indicates that further studies are required, in order to evaluate antigenotoxic activity in vivo, and to isolate these constituents and decipher their mode of action.

\section{Acknowledgments}

This study was financially supported by grants $\mathrm{n}$. 143008 and n. 143002 from the Serbian Ministry of Science.

\section{References}

Brantner A and Grein E (1994) Antibacterial activity of plant extract used externally in traditional medicine. J Ethnopharmacol 44:35-40.

Brendler-Schwaab S, Hartmann A, Pfuhler S and Speit G (2005) The in vivo comet assay: Use and status in genotoxicity testing. Mutagenesis 20:245-254.

Collins AR (2004) Comet assay for DNA damage and repair: Principles applications and limitations. Mol Biotechnol 26:249-261.

Demirci B, Demirci F and Baser KH (2003) Composition of the essential oil of Cotinus coggygria (Scop.) from Turkey. Flavour Fragr J 18:43-44.

Ernst E (2002) Toxic heavy metals and undeclared drugs in Asian herbal medicines. Trends Pharmacol Sci 23:136-139.

Fedeli D, Berrettini M, Gabryelak T and Falcioni G (2004) The effect of some tannins on trout erythrocytes exposed to oxidative stress. Mutat Res 563:89-96.

Gontijo AMMC and Tice R (2003) Comet Assay: Detection of DNA damage and DNA repair in individual cells. In: Ribeiro LR, Salvadori DMF and Marques EK (eds) Mutagênese Ambiental. ULBRA Inc, Canoas, pp 247-275.

Hartmann A, Elhajouji A, Kiskinis E, Poetter F, Martus HJ, Fjällman A, Frieauff W and Suter W (2001) Use of the alkaline comet assay for industrial genotoxicity screening: Comparative investigation with the micronucleus test. Food Chem Toxicol 39:843-858.

Ivanova D, Gerova D, Chervenkov T and Yankova T (2005) Polyphenols and antioxidant capacity of Bulgarian medicinal plants. J Ethnopharmacol 96:145-150.

Kawada M, Ohno Y, Ri Y, Ikoma T, Yuugetu H and Asai T (2001) Anti-tumor effect of gallic acid on LL-2 lung cancer cells transplanted in mice. Anticancer Drugs 12:847-852.

Lewis EB and Bacher F (1968) Method of feeding ethyl methane sulfonate (EMS) to Drosophila males. Drosophila Inf Service 48:193.

Manoharan K and Banerjee MR (1985) $\beta$-carotene reduces sister chromatid exchange induce chemical carcinogens in mouse mammary cells in organ culture. Cell Biol Int Rep 9:783789.

Meyer JJM, Afolayan AJ, Taylor MB and Engelbrecht L (1996) Inhibition of herpes simplex virus type 1 by aqueous extract from shoots of Helichrysum aureonitens (Asteraceae). J Ethnopharmacol 52:41-43.

Novakovic M, VuCkovic I, Janackovic P, Sokovic M, Tesevic V and Milosavljevic S (2007) Chemical composition, antibac- 
terial and antifungal activity of the essential oils of Cotinus coggygria from Serbia. J Serb Chem Soc 72:1045-1051.

Petz B (1985) Basic Statistical Method for Non-mathematical Use. SNL Zagreb, Croatia, 153 pp.

Rayne S and Mazza G (2007) Biological activities of extracts from Sumac (Rhus spp.). Plant Foods Hum Nutr 62:165175.

Singh NP, McCoy MT, Tice RR and Schneider EL (1988) A simple technique for quantitation of low levels of DNA damage in individual cells. Exp Cell Res 175:184-191.

Sohi KK, Mittal N, Hundal MK and Khanduja KL (2003) Gallic acid, an antioxidant, exhibits anti apoptotic potential in normal human lymphocytes: A Bcl-2 independent mechanism. J Nutr Sci Vitaminol 49:221-227.

Stanic S, Muratspahic-Pavlovic D, Solujic S, Comic LJ and Milosevic T (2008) Preliminary results on biological activity of pollen extract of Ambrosia artemisiifolia L. J Biol Res 9:45-53.

Stanic S, Matic S, Solujic S and Milosevic T (2009) Genotoxicity testing of the methanol extract of the plant Cotinus coggygria and gallic acid on Drosophila melanogaster. Arch Biol Sci 61:261-266.

Stathopoulou K, Magitis P, Karapanagiotis I, Valianou L and Chryssoulakis Y (2007) Phytochemical analysis of Cotinus coggygria heartwood. Identification of isolated colorants in historical art objects. Proceedings of the 55th International Congres and Annual Meeting of the Society for Medicinal Plant Research, Austria, Planta Med, pp 163.
Stewart MJ, Moar JJ, Steenkamp P and Kokot M (1999) Findings in fatal cases of poisoning attributed to traditional remedies in South Africa. Forensic Sci Int 101:177-183.

Tice RR, Agurell E, Anderson D, Burlinson B, Hartmann A, Kobayashi H, Miyamae Y, Rojas E, Ryu JC and Sasaki YF (2000) The single cell gel/comet assay: Guidelines for in vitro and in vivo genetic toxicology testing. Environ Mol Mutagen 35:206-221.

Veiga-Junior VF, Pinto AC and Maciel MAM (2005) Medicinal plants: Safe cure? Quim Nova 28:519-528.

Westenburg HE, Lee KJ, Lee SK, Fong HHS, Breemen RBV, Pezzuto JM and Kinghorn AD (2000) Activity-guided isolation of antioxidative constituents of C. coggygria. J Nat Prod 63:1696-1698.

Würgler FE and Graf U (1985) Mutagenicity testing with Drosophila melanogaster. In: Muhammed A and Von Borster RC (eds) Basic and Applied Mutagenesis. Plenum Press, New York, pp 343-372.

\section{Internet Resources}

WHO (2002) Drug Information Herbal Medicines. v. 16. World Health Organization, Geneva. http://apps.who.int/medicinedocs/en/d/Js4950e/ (July 22, 2008).

Associate Editor: Catarina S. Takahashi

License information: This is an open-access article distributed under the terms of the Creative Commons Attribution License, which permits unrestricted use, distribution, and reproduction in any medium, provided the original work is properly cited. 